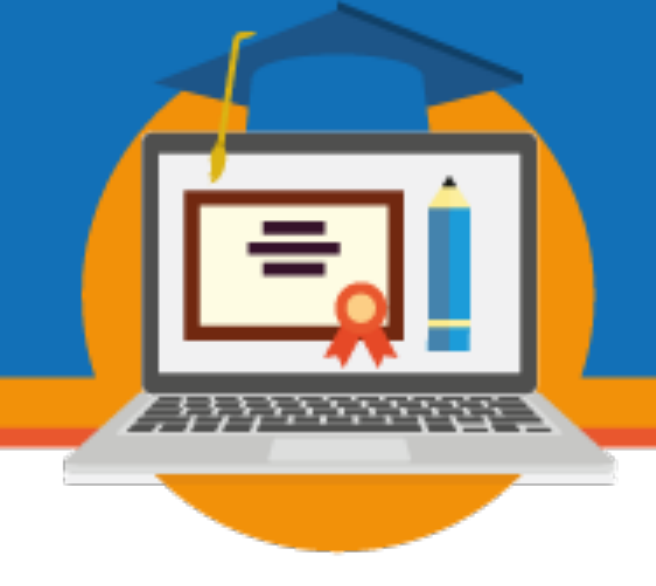

\title{
EDUCAÇÃO A DISTÂNCIA NA PÓS-GRADUAÇÃO STRICTO SENSU E OS MESTRADOS PROFISSIONAIS OFERTADOS PELO PROEB / UAB: PRIMEIRAS REFLEXÕES APÓS LEVANTAMENTO BIBLIOGRÁFICO
}

\author{
Lorena Bernardes Barcelos \\ Universidade Federal de Goiás \\ lorena.ensino@gmail.com
}

Eixo 1: Política, gestão e financiamento da educação a distância

\begin{abstract}
Resumo: Este estudo consiste no levantamento bibliográfico da produção acadêmica sobre a educação a distância na pós-graduação stricto sensu, especialmente os Mestrados Profissionais ofertados através do Sistema Universidade Aberta do Brasil. Este levantamento é a primeira etapa de uma pesquisa que visa compreender a $\mathrm{EaD}$ no stricto sensu, tendo como corpus da análise os Mestrados Profissionais ofertados pela UAB na UFG. O recorte temporal estabelecido foi de 2011 a 2018 e a busca de trabalhos foi feita em diferentes repositórios, a saber: Biblioteca Digital Brasileira de Teses e Dissertações (BDTD) e Catálogo de Teses e Dissertações da Capes, Institute of Education Sciences (ERIC), Repositórios Científicos de Acesso Aberto de Portugal (RCAAP), Portal de Periódicos da Capes e Scielo. Os resultados apontaram um reduzido número de estudos sobre o objeto, o que reforça a necessidade de aprofundamento sobre a temática.
\end{abstract}

Palavras-chave: Stricto sensu. Educação a Distância. ProEB.

\section{Introdução}

Este estudo consiste no levantamento bibliográfico da produção acadêmica sobre a educação a distância na pós-graduação stricto sensu, especialmente os Mestrados Profissionais ofertados através do Sistema Universidade Aberta do Brasil. O levantamento é a primeira etapa de uma pesquisa que visa compreender a EaD no stricto sensu, tendo como corpus da análise os Mestrados Profissionais ofertados pela UAB na UFG. Para a busca dos trabalhos, foi definido o recorte temporal entre os anos de 2011 e 2018. A escolha desse período deve-se ao fato de o ProEB ter iniciado em 2011. 


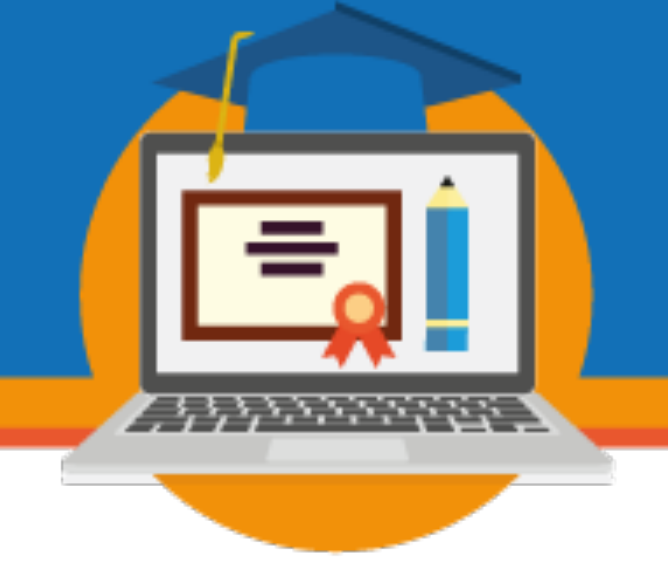

\section{A pós-graduação no Brasil: uma breve reconstituição histórica}

As primeiras iniciativas referentes à pós-graduação no Brasil datam de meados dos anos 1930, com a chegada de professores estrangeiros, que vieram para o país através de missões acadêmicas apoiadas por seus governos, ou em alguns casos, em busca de melhores condições de vida, haja vista o contexto internacional conturbado que antecedeu a Segunda Guerra Mundial (SANTOS, AZEVEDO, 2009).

Esses intelectuais delinearam um modelo de pós-graduação baseado em cátedras ("cadeiras de ensino"), ou seja, através de pequenos grupos de alunos vinculados a um professor catedrático em determinada área do conhecimento. Nesse modelo, ocorria um processo de estudos e orientação informal, e o foco principal era o desenvolvimento de uma tese relativa à cátedra. (SAVIANI, 2000).

Essas experiências não tiveram muito impacto no ensino superior brasileiro. Assim, na intenção de fortalecer o cenário da pós-graduação no Brasil, foram criadas duas instituições voltadas ao aperfeiçoamento de pessoal e estímulo a investigação científica e tecnológica, com a intenção de promover o desenvolvimento do país: o Conselho Nacional de Desenvolvimento Científico e Tecnológico - CNPq e a Campanha Nacional de Aperfeiçoamento de Pessoal de Nível Superior, atual Coordenação de Aperfeiçoamento de Pessoal de Nível Superior - Capes.

O CNPq foi criado em 15 de janeiro de 1951, através da Lei $n^{\circ} 1.310$, tendo como principais finalidades a promoção, o estímulo e o desenvolvimento da investigação científica e tecnológica, mediante a concessão de recursos para pesquisa, formação de pesquisadores e técnicos, cooperação com as universidades brasileiras e intercâmbio com instituições estrangeiras (BRASIL, 2015).

Em 11 de julho de 1951, foi criada a Capes, com o objetivo de "assegurar a existência de pessoal especializado em quantidade e qualidade suficientes para atender às necessidades dos empreendimentos públicos e privados que visam ao desenvolvimento do país" (BRASIL, 2015). 
Em 1965, durante o Regime Militar, o Ministério da Educação aprovou o Parecer n ${ }^{\circ}$ 977/1965, a partir dos pressupostos da Lei de Diretrizes e Bases da Educação vigente (de 1961), tendo como relator o Professor Newton Sucupira (por isso o nome pelo qual o documento é conhecido). Esse Parecer não apenas conceituou, mas institucionalizou a pós-graduação brasileira nos moldes como é até os dias de hoje.

Embora institucionalizada e "regulamentada" em pleno Regime Militar, no contexto da Reforma Universitária, conforme destacam Alves e Oliveira (2014 p.362), “a pós-graduação assume o lócus de elitização da educação superior, mas também de afirmação da pesquisa como uma das dimensões indissociáveis do trabalho docente na educação superior".

\section{Os mestrados profissionais na pós-graduação brasileira}

A evolução da pós-graduação brasileira levou ao desenvolvimento de diversos tipos de cursos, de lato sensu (especializações) e strictu sensu (mestrados e doutorados). No rol dos cursos strictu sensu, situam-se os Mestrados Profissionais, criados no Brasil pela Capes, por meio da Portaria $\mathrm{n}^{\circ} 47 / 1995$, que determinava a implantação de procedimentos apropriados à recomendação, acompanhamento e avaliação de cursos de mestrado dirigidos à formação profissional. Os MPs foram, posteriormente, regulamentados por meio da Portaria $\mathrm{n}^{\circ}$ 80/1998 (revoga a Portaria anterior e dispõe sobre o reconhecimento dos MPs) e, por fim, pela Portaria $n^{\circ} 7 / 2009$.

Esses cursos são caracterizados pela disseminação do ensino (em detrimento da pesquisa) e pela formação de profissionais "qualificados" para a atuação no mercado, ao contrário dos egressos dos mestrados acadêmicos, formados para a pesquisa e para o fazer científico.

Críticos dos MPs apontam que esta modalidade de pós-graduação representa um estreitamento da (indesejável) relação entre a Universidade e o mercado. O texto da Portaria 7/2009, de fato, sugere essa relação. Por outro lado, há os mais comedidos, como Ribeiro (2010), para quem essa relação só se fortalece se as universidades assim permitirem, pois, na verdade, os MPs trazem o desenvolvimento de novas competências e contribuições sociais e 


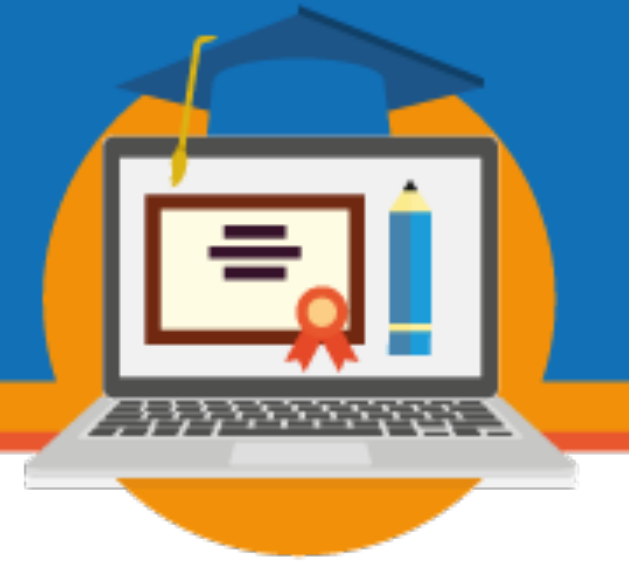

direcionam a pós-graduação para uma orientação mais coletivista e prática.

Atualmente, a Portaria $n^{\circ} 389 / 2017$, do Ministério da Educação, e a Portaria $n^{\circ}$ 131/2017, da Capes, dispõem sobre os mestrados e doutorados profissionais. A Resolução CNE/CSE 7/2017, por sua vez, reordena os cursos de pós-graduação stricto sensu. Os referidos documentos refletem um conjunto de ações políticas e alterações na base legal que incentivam e favorecem a expansão da pós stricto sensu, especialmente nas modalidades profissional e a distância. Essas novas diretrizes sinalizam a necessidade de aprofundamento nos estudos sobre a pós-graduação e sobre os recentes movimentos em relação aos MPs e à modalidade de EaD como via para este nível de ensino.

\title{
A EaD e a pós-graduação stricto sensu
}

Para discutir o Sistema Universidade Aberta do Brasil, faz-se necessário, antes, discorrer, ainda que brevemente, sobre a Educação a Distância no país'. Quanto ao aspecto legal, a EaD foi regulamentada, inicialmente, pela Lei de Diretrizes e Bases da Educação Nacional (LDB, Lei n ${ }^{\circ}$ 9394, de 20 de dezembro de 1996), cujo artigo 80 declarava que o Poder Público incentivaria o desenvolvimento e a oferta da $\mathrm{EaD}$ em todos os níveis de ensino. Dado o caráter sucinto do Artigo 80, o mesmo foi regulamentado pelo Decreto $\mathrm{n}^{\circ} 5622 / 2005$, que ampliou a abordagem da Educação a Distância, definindo-a como

\begin{abstract}
modalidade educacional na qual a mediação didático-pedagógica nos processos de ensino e aprendizagem ocorre com a utilização de meios e tecnologias de informação e comunicação, com estudantes e professores desenvolvendo atividades educativas em lugares ou tempos diversos. (BRASIL, 2005).
\end{abstract}

Mais recentemente, o Decreto 9057, de 25 de maio de 2017, revogou o Decreto $\mathrm{n}^{\circ}$ 5622/2005 e regulamentou, novamente, o Artigo 80 da Lei 9394/96, reconfigurando, de modo mais simples e menos burocrático, os aspectos legais da Educação a Distância no Brasil. Alguns estudiosos deste campo chegaram a afirmar que, na verdade, o novo Decreto propõe a

1 Aqui não retomaremos os primórdios da $\mathrm{EaD}$, desde os cursos por correspondência ou via rádio. Sobre a constituição histórica da EaD, sugere-se a leitura de Sousa (2016).

\section{SEMINÁRIO DE EDUCAÇÃO A DISTÂNCIA}




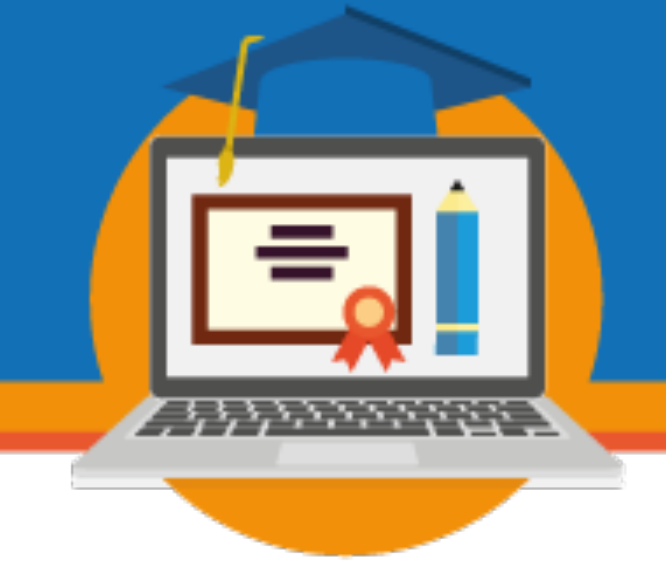

"desregulamentação" da modalidade, e acena para um cenário de expansão da EaD, correspondendo à lógica do mercado.

Dada a necessidade e a importância de compreender a EaD em sua amplitude, considerando-se todas as suas interfaces, a modalidade é definida por Lima (2014a, p. 60) como

uma prática social-educativa-dialógica de um trabalho coletivo, de autoria e colaborativo, articulada para o desenvolvimento de uma arquitetura pedagógica e de gestão, integrada ao uso significativo das tecnologias de informação e comunicação, voltada para a formação crítica, autônoma e emancipadora.

No contexto atual, e observando-se o objeto deste estudo, Oliveira e Lima (2018, p. 232233) apontam que

Um dos aspectos mais marcantes na Resolução CNE 7/2017 é a oferta de Mestrados e Doutorados por meio da modalidade $\mathrm{EaD}$, o que antes não era normatizado. [...]Especial ênfase é dada à modalidade de cursos profissionais, assim como foi feito com a modalidade a distância e associativa.

Essa nova orientação da pós-graduação no Brasil, bem como a desburocratização da EaD permitida pelo Decreto $\mathrm{n}^{\circ}$ 9057/2017, reforçam a necessidade discutir e ampliar os estudos acerca dos dois objetos (pós-graduação stricto sensu e EaD), com vista a preservar a qualidade da pós-graduação brasileira e seu reconhecimento nacional e internacional. É importante ressaltar, aqui, que a modalidade $\mathrm{EaD}$, por si, não compromete a qualidade do sistema de pósgraduação stricto sensu. Ao contrário, se adequadamente implementada, contribuirá para a expansão desse sistema. O que poderia representar riscos à reconhecida qualidade da pósgraduação no Brasil é, justamente, a expansão mercantilista, que empregaria a modalidade de educação a distância para crescer em números, observando-se a demanda pela formação nesse nível de ensino, em detrimento da qualidade dos programas ofertados.

\section{A Universidade Aberta do Brasil (UAB)}

A Universidade Aberta do Brasil (UAB) foi instituída pelo Decreto $\mathrm{n}^{\circ} 5800$, de 8 de junho de 2006, para viabilizar o desenvolvimento da Educação a Distância, com vista à expansão e interiorização do ensino superior no país. Uma das pretensões do Sistema UAB era fomentar a EaD na rede pública de ensino superior, estimulando a criação de centros de 


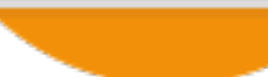

formação permanentes por meio dos polos de $\mathrm{EaD}$ em localidades estratégicas, contribuindo para o fortalecimento e institucionalização da modalidade.

Através da interiorização da educação superior, na modalidade a distância, a meta principal da UAB era contribuir para a Política Nacional de Formação de Professores do Ministério da Educação - PARFOR, por isso, as ofertas de vagas são prioritariamente voltadas para a formação inicial e continuada de professores da educação básica, para tanto, foram implementados diferentes programas, dentre os quais, está o ProEB (Programa de Mestrado Profissional para Qualificação de Professores - ProEB), que teve início em 2011, com o objetivo de promover a formação continuada stricto sensu dos professores em exercício na rede pública de Educação Básica.

O ProEB está contemplado no Plano Nacional de Educação (PNE 2014-2024)² em três de suas metas (que estão vinculadas à pós-graduação stricto sensu): a Meta 14 (elevar gradualmente o número de matrículas neste nível de ensino), a Meta 13 (ampliar o número de mestres e doutores do corpo docente da Educação Superior) e a Meta 16 (garantir a formação continuada dos professores da Educação Básica, com ênfase na pós-graduação, sobretudo no Mestrado).

O primeiro programa de MP ofertado no âmbito da UAB foi o Mestrado Profissional em Matemática em Rede Nacional (PROFMAT), iniciado em 2011, para os professores de Matemática. Em 2015, foi instituído o Programa Nacional de Mestrado Profissional em Ensino de Física (ProFis / MNPEF), voltado para os professores de Física.

Atualmente, além do PROFMAT e do ProFis, há 8 programas de MP na área da Educação, a saber: Profletras - MP em Letras; ProfArtes - MP em Artes; ProfHistória - MP em Ensino de História; PROFBIO - MP em Ensino de Biologia; PROFQUI - MP em Química; PROFilo - MP em Filosofia; PROFSOCIO - MP em Sociologia; PROEF - MP em Ensino de Educação Física.

\section{Encaminhamento metodológico: o levantamento bibliográfico}

${ }^{2}$ Aprovado pela Lei 13.005/2014.

III SEMINÁRIO DE EDUCAÇÃO A DISTÂNCIA

Diálogos sobre EaD e uso das TDIC na educação: regulamentação em tempos recentes

3 a 6 de novembro de 2020 - Brasília/DF - Online 


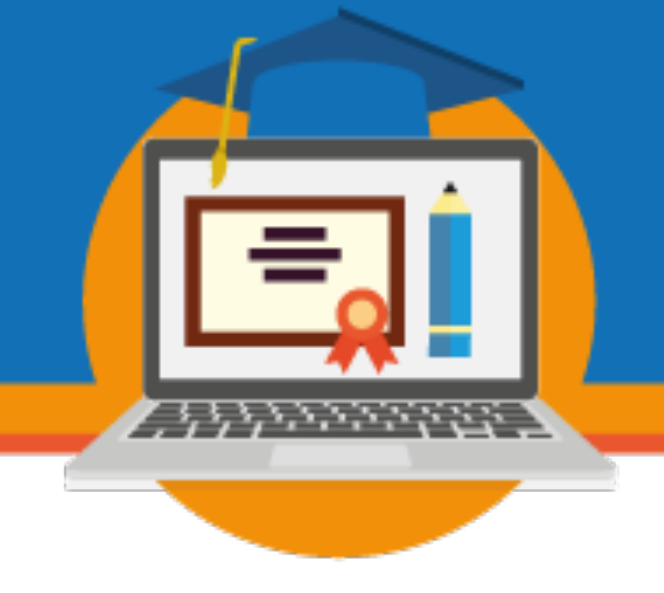

\section{Resultados e discussão}

O levantamento realizado na Biblioteca Digital de Teses e Dissertações (BDTD) e no Catálogo de Teses e Dissertações da Capes apontou um grande número de trabalhos finais dos próprios alunos dos MPs. Todos os resumos foram analisados e observou-se que tratavam-se de "produtos educacionais" apresentados como requisito para a obtenção do título de Mestre. Estes não foram catalogados para uso nesta pesquisa pois, aqui, o objetivo é estudar o Programa, em si.

Além dos trabalhos de conclusão dos alunos do ProEB, foram encontrados 83 estudos. Desse universo, 75 trabalhos versam sobre outro programa, do estado de Minas Gerais, que tem a mesma sigla, ProEB. Trata-se do Programa de Avaliação da Rede Pública de Educação Básica - ProEB, vinculado ao Sistema Mineiro de Avaliação e Equidade da Educação Pública SIMAVEs.

No Catálogo de Teses e Dissertações da Capes foram encontrados 7 trabalhos que, de alguma forma, relacionam-se com a pesquisa pretendida. Tratam-se de 2 teses e 5 dissertações. Deste conjunto, destacamos 2 trabalhos pela relevância quanto ao nosso objeto.

O primeiro deles é a tese intitulada $O$ mestrado profissional em ensino na formação continuada: da motivação docente à escola, defendida por Bruno Teles Nunes, na Universidade Católica de Brasília, em 2017. Em seu estudo, de caráter exploratório, o autor apresenta um cenário do potencial de efetividade do Programa de Mestrado Profissional para Qualificação de Professores da Rede Pública da Educação Básica (ProEB). O cenário é composto por quatro elementos: o perfil motivacional dos professores; a percepção dos mesmos acerca: de aspectos acadêmicos dos mestrados; da contribuição da experiência nos cursos para a prática docente; e da permeabilidade dos contextos escolares aos novos saberes. O trabalho é relevante pois, para proceder à discussão proposta, Nunes reconstrói o panorama das políticas públicas para

${ }^{5}$ Disponível em: http://www.simave.caedufjf.net/.

\section{SEMINÁRIO DE EDUCAÇÃO A DISTÂNCIA}


formação de professores no Brasil, até o ProEB, que destaca-se como a primeira política pública, de abrangência nacional, voltada à formação continuada de professores da educação básica em nível stricto sensu.

O segundo trabalho encontrado no Catálogo de Teses e Dissertações da Capes relevante para a pesquisa que propomos é a tese de Andrea Midori Takai, intitulada Perspectivas do PROFMAT: política pública em construção, defendida em 2017 na Universidade Federal do Rio Grande do Sul. Em seu estudo, Takai analisa o PROFMAT sob o prisma do ciclo da política pública. Para isso, refaz o histórico da pós-graduação no Brasil passando detalhadamente por todos os Planos Nacionais de Pós-Graduação - PNPG.

Na Biblioteca Digital de Teses e Dissertações - BDTD, foram encontrados 7 trabalhos, sendo 3 teses e 4 dissertações. Dentre os trabalhos encontrados na BDTD, destacamos dois como possível referencial teórico para nosso estudo. O primeiro deles é a dissertação defendida em 2015, por Georgina Marafante Sá, na Universidade Federal de Pernambuco, intitulada Educação a distância em instituições de ensino superior federais: aproximações $e$ distanciamentos para a institucionalização. Neste estudo, a autora reconstitui o histórico da UAB como uma das vias de inserção da educação a distância nas universidades públicas brasileiras.

O segundo trabalho encontrado na BDTD também foi relacionado na busca realizada no Catálogo de Teses e Dissertações da Capes. Trata-se da dissertação defendida em 2011 por Vanessa Itacaramby Pardim, intitulada $O$ uso da educação online como alternativa para os programas de pós-graduação stricto sensu no Brasil. Através de um estudo de caso, a autora analisou como a coordenação e os alunos e um programa de pós-graduação stricto sensu semipresencial percebiam o uso da educação online. O estudo de Pardim é interessante pois, já em 2011, a autora observou a escassez de trabalhos com temática semelhante. O levantamento bibliográfico por ela realizado passou pelas mesmas bases visitadas em nosso levantamento, o que permite-nos afirmar que, de fato, a EaD no stricto sensu é um tema ainda pouco explorado pela academia.

No Portal de Periódicos da Capes foram encontrados 7 artigos convergentes à temática 
da pesquisa aqui pretendida. Após a leitura dos mesmos, um deles foi selecionado para referenciar nossas reflexões: A percepção dos docentes frente a Educação a Distância no Stricto Sensu (Pimenta e Silva, 2011). Neste estudo, realizado em caráter exploratório, os autores concluíram que, diante do crescimento da Educação a Distância, a modalidade se consolidará também no stricto sensu, entretanto, com a ressalva de que seja empregada na "forma híbrida". Temos, aqui, uma ressalva: o híbrido não é uma modalidade da EaD. Educação presencial, a distância e híbrida são modalidades distintas e serão, em nosso estudo, oportunamente caracterizadas.

No Scielo, foram encontrados 3 trabalhos relacionados à temática aqui pretendida. Dentre eles, destacamos o artigo Formação de educadores a distância na pós-graduação: potencialidades para o desenvolvimento da investigação e produção de conhecimento, publicado em 2012 por Maria Elizabeth Bianconcini de Almeida. O estudo, altamente relevante para a nossa pesquisa, tem por objetivo discutir as potencialidades e limitações de cursos de pós-graduação a distância em uma análise nas dimensões das políticas públicas, dos fundamentos e resultados de investigações científicas, buscando fornecer subsídios para o desenvolvimento de programas que possam ter como princípios básicos a investigação e a produção do conhecimento. O texto está estruturado em três partes: visão geral das políticas, regulamentação e estrutura da educação a distância no ensino superior brasileiro; princípios da interação, reflexão, investigação, colaboração e construção do conhecimento; contribuições para a realização de cursos de pós-graduação a distância.

Na plataforma ERIC, foram encontrados 12 trabalhos que tangenciam em algum ponto a temática que pretendemos discutir. Tratam-se de 11 artigos e 1 dissertação. Entretanto, todos são de acesso restrito (acesso mediante pagamento direto ao periódico em que foram publicados). Pela leitura dos resumos disponíveis, 3 trabalhos parecem ser interessantes para esta pesquisa, e sua aquisição para leitura será analisada posteriormente. São eles: Faculty Concerns Related to Distance Learning within Nontraditional Doctoral Programs (Preocupações do corpo docente relacionadas ao ensino a distância em programas de doutorado 


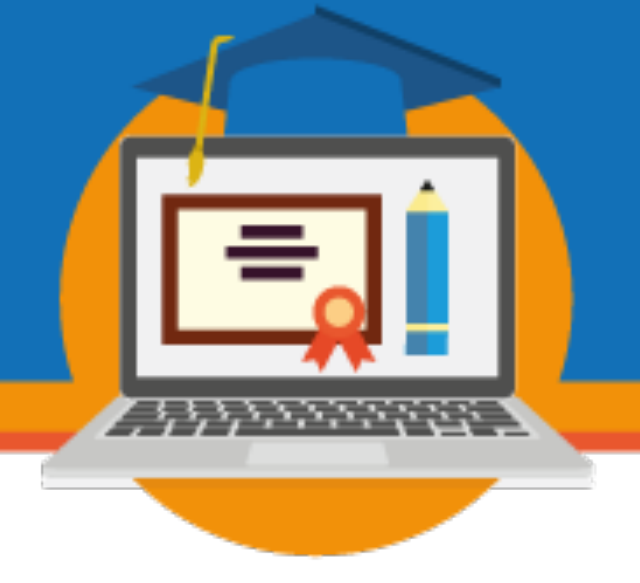

não tradicionais) ${ }^{6}$, The "Dissertation Marathon" in Doctoral Distance Education (A "Maratona de Dissertação" na Educação a Distância Doutoral)’ e Student Satisfaction with Graduate Supervision in Doctoral Programs Primarily Delivered in Distance Education Settings (A satisfação do aluno com a supervisão de pós-graduação em programas de doutorado ministrados principalmente em instituições de ensino à distância) $)^{8}$.

No RCAAP foram encontrados 17 trabalhos, que foram desconsiderados por trataremse de trabalhos finais de Mestrados Profissionais em universidades de Portugal. A maior parte destes trabalhos consiste de Relatórios de Atividade Profissional em Meio Ambiente ou Tecnologia Ambiental.

O levantamento feito aponta que a Educação a Distância no stricto sensu, bem como os mestrados profissionais do ProEB, ainda são temas pouco contemplados pela academia. $\mathrm{O}$ ProEB, em si, é pouco discutido nos trabalhos consultados, nos quais o foco recai sobre o PROFMAT e as contribuições deste programa para o ensino de Matemática no Brasil. Enquanto política pública e com o foco na modalidade de educação a distância, observa-se que o ProEB ainda é pouco explorado, carecendo de maior aprofundamento pela comunidade científica.

\footnotetext{
${ }^{6}$ Singleton, H. Wells; Session, Carmen L., 2011. Disponível em: https://onlinelibrary.wiley.com/doi/abs/10.1002/ace.398.

${ }^{7}$ Tweedie, M. Gregory; Clark, Sheila; Johnson, Robert C.; Kay, D., 2013. Disponível em: https://www.eric.ed.gov/?q=+\%22doctoral + programs $\% 22+\% 22$ distance + education $\% 22 \& \mathrm{id}=\mathrm{EJ} 1023966$ ${ }^{8}$ Erichsen, Elizabeth Anne; Bolliger, Doris U.; Halupa, Colleen, 2014. Disponível em: www.eric.ed.gov/?q=+"doctoral+programs"+"distance+education"\&id=EJ1027373.
} 


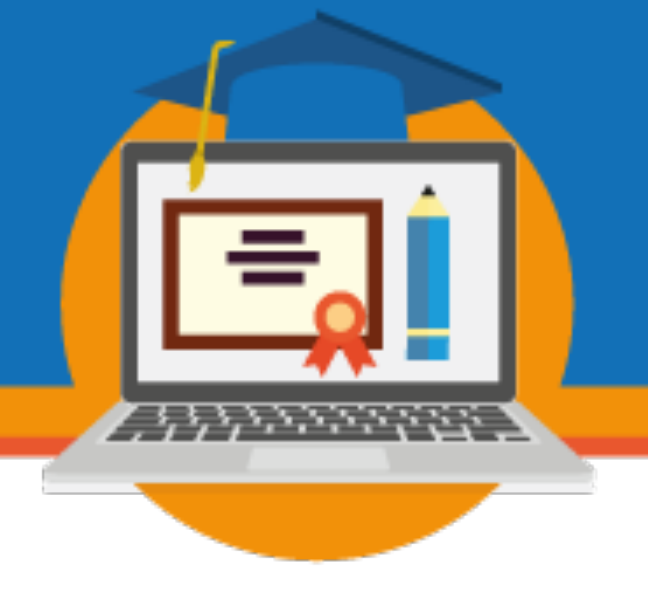

\section{Referências}

ALVES, M. F.; OLIVEIRA, J. F. Pós-Graduação no Brasil: do Regime Militar aos dias atuais. Revista Brasileira de Política e Administração da Educação - Periódico científico editado pela ANPAE, [S.1.], v. 30, n. 2, fev. 2014. Disponível em: <http://seer.ufrgs.br/index.php/rbpae/article/view/53680>. Acesso em: 29 nov. 2018.

ALMEIDA, Maria Elizabeth Bianconcini de. Formação de educadores a distância na pósgraduação: potencialidades para o desenvolvimento da investigação e produção de conhecimento. Educação e Sociedade, Campinas , v. 33, n. 121, p. 1053-1072, Dec. 2012. Acesso em: 29 dez 2019.

BRASIL. Decreto no 5.622, de 19 de dezembro de 2005. Diário Oficial República Federativa do Brasil. Brasília, 20 de dezembro. Disponível em: http://www.planalto.gov.br/ccivil_03/Ato2004-2006/2005/Decreto/D5622.htm. Acesso em: 21 mar. 2018.

BRASIL. Decreto no 5.707, de 23 de fevereiro de 2006. Institui a Política e as Diretrizes para o Desenvolvimento de Pessoal da administração pública. Diário Oficial República Federativa do Brasil. Brasília, 24 fev. 2006. Seção 1, p. 3-4.Disponível em: http://www.planalto.gov.br/ccivil 03/ Ato2004-2006/2006/Decreto/D5707.htm. Acesso em: 29 nov. 2018.

BRASIL. Decreto 5.800, de 8 de junho de 2006. Dispõe sobre o Sistema Universidade Aberta do Brasil. Disponível em: http://www.planalto.gov.br/ccivil_03/Ato20042006/2006/Decreto/D5800.htm. Acesso em: 29 nov. 2018.

BRASIL. Lei $\mathbf{n}^{0}$ 1.310, de 15 de janeiro de 1951. Cria o Conselho Nacional de Pesquisa. Disponível em: http://www.planalto.gov.br/ccivil 03/leis/1950-1969/L1310.htm. Acesso em: 21 mar. 2018.

BRASIL. Lei no 9.394, de 20 de dezembro de 1996. Lei de Diretrizes e Bases da Educação Nacional. 1996. Disponível em: http://www.planalto.gov.br/ccivil_03/LEIS/L9394.htm. Acesso em: 21 mar. 2018.

BRASIL. Lei no 13.005, de 25 de junho de 2014. Aprova o Plano Nacional de Educação - PNE e dá outras providências. Diário Oficial da União, Brasília, DF, 26 jun. 2014. Disponível em: 


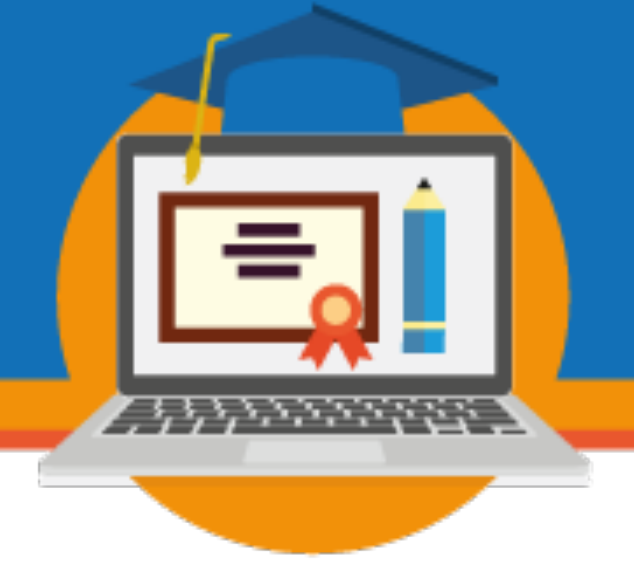

http://www.planalto.gov.br/ccivil 03/ Ato2011-2014/2014/Lei/L13005.htm. Acesso em: 29 nov. 2018.

BRASIL. Parecer CFE n 977/1965, aprovado em 3 dez. 1965. Revista Brasileira de Educação. n.30, p. 162-173. Disponível em: http://www.scielo.br/pdf/rbedu/n30/a14n30.pdf. Acesso em: 29 nov. 2018.

BRASIL. Portaria no 47, de 17 de outubro de 1995. Determina a implantação na Capes de Procedimentos apropriados à recomendação, acompanhamento e avaliação de cursos de mestrado dirigidos à formação profissional. Brasilia, DF. Disponível em: http://ojs.rbpg.capes.gov.br/index.php/rbpg/article/view/87/83\%20Acesso\%20em\%2022.

Acesso em: 29 nov. 2018.

BRASIL. Portaria no 7, de 28 de dezembro de 2009. Dispõe sobre o mestrado profissional no âmbito da Fundação Coordenação de Aperfeiçoamento de Pessoal de Nível Superior - CAPES. Diário Oficial da União. 248. ed. Brasília, DF: Imprensa Nacional, 29 dez. 2009. n. 248, Seção 1, p. 20-21.Disponível em: http://capes.gov.br/images/stories/download/legislacao/16112018 PortariaNormativa n\%C2 \%BA17.pdf. Acesso em: 29 nov. 2018.

BRASIL. Resolução CNE/CES n. 2, de 18 de dezembro de 2002. Altera a redação do parágrafo $4^{\circ}$ do artigo $1^{\circ}$ e o artigo $2^{\circ}$ da Resolução CNE/CES 1/2001, que estabelece normas de funcionamento de cursos de pós-graduação stricto sensu. Disponível em: https://www.capes.gov.br/images/stories/download/legislacao/RESOLUCAO_CES_24_2002. pdf.. Acesso em: 29 nov. 2018.

LIMA, D. C. B. P. Políticas públicas de EaD no ensino superior: uma análise a partir das capacidades do Estado. 2013. 285 f. Tese (Doutorado em Políticas Públicas, Estratégias e Desenvolvimento) - Programa de Pós Graduação em Políticas Públicas, Estratégias e Desenvolvimento, Instituto de Economia, Universidade Federal do Rio de Janeiro, Rio de Janeiro, 2013.

LIMA, D. C. B. P. Documento técnico contendo estudo analítico do processo de expansão de EaD ocorrido no período de 2002-2012, particularmente no que se refere aos cursos de formação de professores nas IES públicas e privadas. Produto 02, 2014. Projeto Conselho Nacional de Educação/Organização das Nações Unidas para a Educação, a Ciência e a Cultura. Brasília, CNE, 2014a. Disponível em:

http://mecsrv125.mec.gov.br/index.php?option=com docman\&task=doc download\&gid=16 510\&Itemid $=$. Acesso em: 29 nov .2018. 


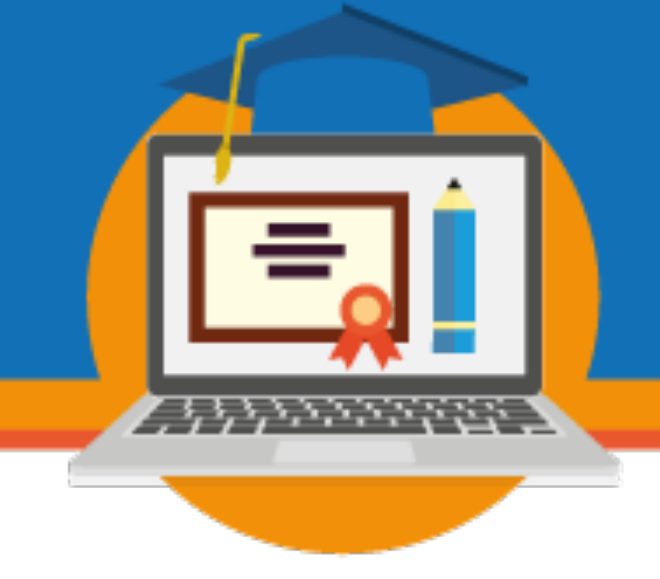

OLIVEIRA, J. F.; LIMA, D. C. B. P. Pós-graduação e educação à distância: novos fins, natureza e modus operandi em construção. Educação Superior em países e regiões de língua portuguesa: desafios em tempo de crise. Lisboa: Educa, 2018, v. 1, p. 215-244.

NUNES, B. T. O mestrado profissional em ensino na formação continuada: da motivação docente à escola. Tese (Doutorado). Universidade Católica de Brasília, 2017. Disponível em: https://sucupira.capes.gov.br/sucupira/public/consultas/coleta/trabalhoConclusao/viewTrabalh oConclusao.jsf?popup=true\&id trabalho=5192870. Acesso em 08 Jan 2020.

PARDIM, V. I. O uso da educação online como alternativa para os programas de pósgraduação stricto sensu no Brasil. Dissertação (Mestrado). Universidade Nove de Julho UNINOVE, São Paulo, 2011. Disponível em: http://repositorio.uninove.br/xmlui/bitstream/handle/123456789/291/VANESSA\%20ITACA RAMBY\%20PARDIM\%202011.pdf?sequence=1. Acesso em 12 dez 2019.

PIMENTA, I. L., \& SILVA, C. A. B. (2011). A percepção dos docentes frente a Educação a Distância no Stricto Sensu. Revista Espaço Acadêmico, 11(127), 56-64. Disponível em: http://periodicos.uem.br/ojs/index.php/EspacoAcademico/article/view/13453. Acesso em 08 Jan 2020 .

SÁ, G. M. Educação a distância em instituições de ensino superior federais: aproximações e distanciamentos para a institucionalização. Dissertação (Mestrado) - Universidade Federal de Pernambuco, CE. Programa de Pós-graduação em Educação Matemática e Tecnológica, 2015. Diponível em: https://repositorio.ufpe.br/bitstream/123456789/17378/1/Dissertacao Georgina Marafante S a 2015 EDUMATEC.pdf. Acesso em 12 Dez. 2019.

SANTIN, R. H. BASSANI, G. A EaD e a pós-graduação stricto sensu a distância no Brasil: uma abordagem teórica. Revista CESUMAR (Ciencias Humanas e Sociais Aplicadas) . janjun2018, Vol. 23 Issue 1, p113-132. 20p. Disponível em: https://periodicos.unicesumar.edu.br/index.php/revcesumar/article/view/6174. Acesso: 07 Jan 2020.

SANTOS, A. L. F. AZEVEDO, J. M. L. A pós-graduação no Brasil, a pesquisa em educação e os estudos sobre a política educacional: contornos da constituição de um campo acadêmico. Revista Brasileira de Educação, v. 14, n. 42. P. 534-605, set/dez. 2009. Disponível em: http://www.scielo.br/pdf/rbedu/v14n42/v14n42a10.pdf. Acesso em: 21 mar 2018.

SOUSA, L. S. L. Constituição e desenvolvimento da educação superior a distância no Brasil: as contribuições do Conselho Federal de Educação (1962 - 1994) e do Conselho Nacional de Educação (1995-2014). 2016. 194 f. Dissertação (Mestrado em Educação Linguagem e Tecnologias). Universidade Estadual de Goiás, Anápolis, Goiás, 2016. 


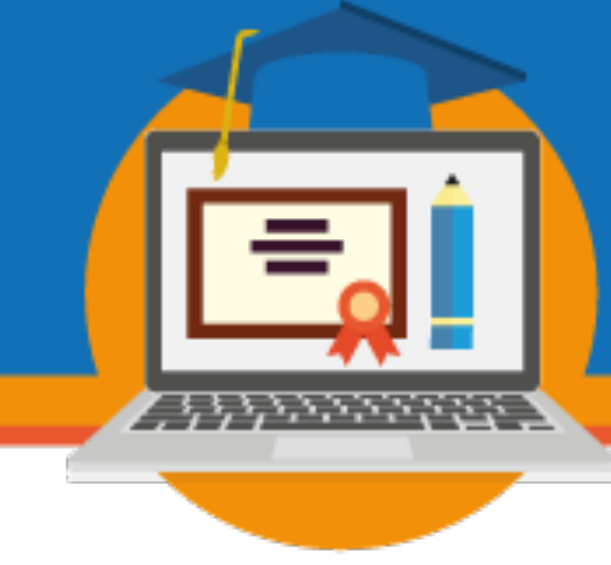

TAKAI, A. M. Perspectivas do PROFMAT: política pública em construção. Tese (Doutorado). Universidade Federal do Rio Grande do Sul. Porto Alegre, 2017. Disponível em: https://www.sbm.org.br/colecoes/perspectivas-do-PROFMAT-politica-publica-emconstrucao. Acesso em $21 \mathrm{dez} 2019$.

VOSGERAU, S. R. D.; ROMANOWSKI, J. P. Estudos de revisão: implicações conceituais e metodológicas. Revista Diálogo Educacional, [S.1.], v. 14, n. 41, p. 165-189, jul. 2014. ISSN 1981-416X. Disponível

em: https://periodicos.pucpr.br/index.php/dialogoeducacional/article/view/2317/2233. Acesso em: 19 Fev. 2019. 